\title{
Intraocular pressure of adults in a coastal province in southern China: the Fujian cross-sectional eye study
}

\author{
Yang $\mathrm{Li}^{1,2 \#}$, Qinrui $\mathrm{Hu}^{1,2 \#}$, Xiaoxin $\mathrm{Li}^{2,3}$, Yonghua $\mathrm{Hu}^{1}$, Bin Wang ${ }^{2}$, Xueying Qin ${ }^{1}$, Tao Ren ${ }^{1}$ \\ ${ }^{1}$ Department of Epidemiology and Biostatistics, School of Public Health, Peking University Health Science Centre, Beijing, China; ${ }^{2}$ Xiamen Eye \\ Center Affiliated with Xiamen University, Xiamen, Fujian, China; ${ }^{3}$ Department of Ophthalmology, Peking University People's Hospital, Beijing, \\ China \\ Contributions: (I) Conception and design: Y Li, Q Hu; (II) Administrative support: X Li, Y Hu; (III) Provision of study materials or patients: None; (IV) \\ Collection and assembly of data: Y Li, Q Hu, B Wang, X Qin, T Ren; (V) Data analysis and interpretation: Y Li, Q Hu; (VI) Manuscript writing: All \\ authors; (VII) Final approval of manuscript: All authors. \\ \#These authors contributed equally to this work. \\ Correspondence to: Xiaoxin Li, MD, PhD. Xiamen Eye Center Affiliated with Xiamen University, 336 Xiahe Road, Siming District, Xiamen 361003 , \\ China; Department of Ophthalmology, Peking University People's Hospital, 44 Xizhimennei Street, Xicheng District, Beijing 100044, China. \\ Email: drlixiaoxin@163.com; Yonghua Hu, MD, PhD. Department of Epidemiology and Biostatistics, School of Public Health, Peking University \\ Health Science Centre, 38 Xueyuan Road, Haididan District, Beijing 100191, China. Email: yhhu@bjmu.edu.cn.
}

Background: Glaucoma is a leading cause of irreversible vision loss worldwide. Increased intraocular pressure (IOP) is widely recognized as the most important modifiable risk factor for the development of glaucoma. In order to arouse people's attention to glaucoma, this study set out to describe IOP and its related factors in adults living in urban and rural areas of Fujian, a coastal province in southern China.

Methods: A population-based cross-sectional study (the Fujian Eye Study) was conducted from May 2018 to October 2019. The study enrolled 10,044 residents of Fujian aged 50 years and over to participate in a questionnaire and a series of physical and ocular examinations, such as height, weight, heart rate (HR), systolic blood pressure (SBP), diastolic blood pressure (DBP), visual acuity (VA), IOP, slit lamp and fundus examinations. Participants were divided into subgroups by age, sex, region, refraction, and other characteristics. IOP was measured with the handheld iCare rebound tonometer.

Results: A total of 8,211 individuals were included, of whom 8,153 underwent IOP examination. The mean IOP was $13.88 \pm 3.46 \mathrm{mmHg}$ (median, $14 \mathrm{mmHg}$; range, 5-57 mmHg). Multiple regression analysis revealed that IOP was associated with age, sex, refraction, SBP, living in an inland area, smartphone use in the dark, and a history of chronic diseases. However, IOP was statistically independent of living in an urban or rural area, body mass index, DBP, tobacco use, alcohol use, and tea consumption.

Conclusions: Additional vision-related policies targeting younger women, people with high SBP, myopia, and chronic diseases, and those living in inland areas are needed in future.

Keywords: Intraocular pressure (IOP); related factor; coastal and inland; urban and rural; smartphone use in the dark

Submitted Oct 13, 2021. Accepted for publication Nov 25, 2021.

doi: 10.21037/apm-21-3238

View this article at: https://dx.doi.org/10.21037/apm-21-3238

\section{Introduction}

Glaucoma describes a group of sight-damaging eye disorders and is a chief cause of irreversible vision loss worldwide. It affects more than 70 million people worldwide, approximately $10 \%$ of whom are bilaterally blind (1). Visual impairment in patients with glaucoma is mainly caused by optic nerve damage resulting from high intraocular pressure (IOP) (2). 
IOP, the pressure within the eyeball, is mainly regulated through the production and elimination of aqueous humor. A balanced IOP aids in maintaining the eyeball contour, which allows for proper refraction of light in the anterior segment of the eye. An increase in IOP can damage the ocular structure, typically the optic nerve head and retinal ganglion cells. Increased IOP is widely recognized as the most important modifiable risk factor for the development of glaucoma.

Ethnic and regional differences in IOP are well known to exist. In white European and North American populations, the mean IOP values are higher than those in East Asian populations by approximately 2 to $5 \mathrm{mmHg}(3-6)$. The Asian population has unique ocular anatomic characteristics and a disproportionately high incidence of angle-closure glaucoma, which is associated with a narrow angle (7-10). Several previous studies, including the Singapore Epidemiology of Eye Diseases Study (11), Beijing Eye Study in Northern China (12), Handan Eye Study (13), and Liwan Eye Study (14), have reported the prevalence of high IOP and associations between IOP and characteristics such as age, sex, body mass index (BMI), and systolic blood pressure (SBP) in Asian populations.

The present study aimed to measure IOP and its potential related factors in an adult population in a coastal province of southern China, and to draw detailed comparisons between those living in urban and rural areas, and coastal and inland regions. We found that high IOP was significantly associated with younger age, female sex, faster heart rate (HR), higher SBP, increasing myopia, living in an inland region and smartphone use in the dark. And it was delighted that we found many innovative results, such as IOP was associated with not only age, sex, refraction, SBP, but also living in an inland area, smartphone use in the dark, and a history of chronic diseases. These results may play a guiding role in eye health policy making. We present the following article in accordance with the STROBE reporting checklist (available at https://dx.doi.org/10.21037/apm-21-3238).

\section{Methods}

\section{Sample size considerations}

The Fujian Eye Study (FJES) is a population-based crosssectional study involving adult residents over 50 years from all nine cities in Fujian province, southeast China, which ran from May 2018 to October 2019. Most eye diseases causing vision impairment, especially fundus diseases, mostly occur in the middle-aged and elderly (3-5,7,11,13-16), and the epidemiological survey of the middle-aged and elderly is easier to recruit. Therefore, this epidemiological survey focused on the middle-aged and elderly over the age of 50. The sample size for the study was estimate using the following formula: $\mathrm{n}=\operatorname{deff} \times \mu_{\alpha}^{2} \times \mathrm{p} \times(1-\mathrm{p}) / \mathrm{d}^{2}$. The present study achieved a precision of 0.05 (d), considering a confidence interval (CI) of $95 \%$ (bilateral), $\mu_{\alpha}{ }^{2}$ of 1.96 , design effect of 2 , relative error of 0.15 , and $d=r \times p$. The sample size was calculated to ensure adequate precision of prevalence estimates and permit risk factor analyses to be conducted. At present, the prevalence of major eye diseases in cross-sectional baseline surveys is estimated to exceed $2.0 \%(15,16)$. Given our expectation that $15 \%$ of the residents on the registration lists could not be reached and the abovementioned criteria, 10,044 participants were recruited in this study.

\section{Recruitment procedure}

The 2018-19 FJES protocol was approved by the Ethics Committee of Xiamen Eye Center affiliated with Xiamen University (approval No. XMYKZX-KY-2018-001). The study was conducted in accordance with the Declaration of Helsinki (as revised in 2013). Written informed consent was obtained from all study participants. All participating technicians and clinicians were uniformly trained, and examinations were performed consistently.

The study participants underwent a comprehensive physical examination in a mobile clinic, which was located in a specific location, such as a community center, administrative office, or hospital. The survey collected the following data: demographic information (including age, sex, race, socioeconomic status, income, educational level, history of systemic diseases and eye diseases, personal lifestyle habits, via a questionnaire), IOP, visual acuity (VA) score, the refractive state, and slit lamp and fundus examination results. Socioeconomic status contains economic development level, population distribution, infrastructure status, public facilities, natural environmental factors and so on. Potential differences in economic level, education level, transportation, environmental and lifestyle factors in coastal areas (17-21), the higher comprehensive degrees of sustainable education development in coastal regions and the central-south China (22), and the faster economic development in coastal areas $(23,24)$, may be important factors in the development of vision changes. Six out of nine cities in Fujian province are coastal areas, and eighty percent of Fujian Province is in 
a mountainous area, where transportation is inconvenient and economic and medical resources are limited, so we speculated that IOP may also have potential correlation with socioeconomic factors.

Before the on-site survey, all technicians and clinicians recruited were trained uniformly and needed to finish an examination, and each survey examination was required to be fixed consistently with the same technician. During our on-site survey, participants were asked to complete all the tests before they can get the final diagnosis report, in order to improve the response rate. In the aspect of data collation, double entry with EpiData v3.1 (EpiData for Windows, version 3.1, the EpiData Association, Denmark, Europe) was used to check the data to ensure the correctness of the data. Each resident has a unique identification code to accurately locate their data. We supplemented part of the missing data through telephone follow-up. If we can't contact the resident, it is considered as missing data.

An experienced technician measured participants' IOP with the handheld iCare rebound tonometer (RBT; Icare TA 01, Finland). Quintic measurements were obtained, and their mean was recorded and taken for further statistical analysis.

\section{Statistical analysis}

Data were analyzed with Stata/SE statistical software (Stata for Windows, version 15.1, StataCorp LLC., Lakeway Drive, College Station, TX 77845, USA). Data are presented as the mean \pm standard deviation (SD). Only the data of one randomly selected eye were statistically analyzed unless intraindividual intereye differences were observed. Participants whose IOP was not measured were excluded. Analysis of variance (ANOVA) was applied to compare the mean among groups of normally distributed parameters. Multiple regression models were used to examine the relationships between VA measurements and selected sociodemographic characteristics. Linear regression was used for comparisons of normally distributed parameters. The statistical strength of correlations was reported as correlation coefficient $\mathrm{r}$ or $\mathrm{r}^{2}$, and $95 \%$ CIs were calculated. All associations described relate to multivariable statistical analysis, unless indicated otherwise. A $\mathrm{P}$ value of less than 0.05 was considered statistically significant.

\section{Results}

A total of 8,211 (81.8\%) Fujian residents aged 50 years or above were finally included. IOP data were available for 16,314 eyes of 8,161 participants (response rate, 99.3\%). Figure 1 shows the study recruitment flowchart, and Table 1 shows the composition of the study population. The mean IOP value of the 8,161 participants for whom data were available was $13.88 \pm 3.46 \mathrm{mmHg}$ (median, $14 \mathrm{mmHg}$; range, 5-57 mmHg; Figure 2). In the univariate analysis, the IOP differed significantly $(\mathrm{P}<0.001)$ between the urban and rural groups and between the coastal and inland groups. The IOP did not differ significantly $(\mathrm{P}=0.8864)$ between the right and left eye.

\section{Correlation of IOP with age}

Stratification of the participants by age showed a linear correlation. Intraindividual intereye differences in the IOP (urban group, 0.0028 $\pm 1.61 \mathrm{mmHg}$; rural group, $0.01 \pm 1.94 \mathrm{mmHg})$ decreased significantly with age $(\mathrm{P}<0.05)$. Stratification of the participants by region showed that the mean IOP was significantly higher in the rural group than in the urban group in the 60-64 and $>80$ years subgroups, and it was significantly higher in the inland group than in the coastal group among those aged under 65 years (Table 2).

\section{Correlation of IOP with refraction}

Classification of the study population into subgroups by refraction revealed a higher IOP in the myopic group than in the hyperopic group. Regional stratification showed that in the mild myopia and mild hyperopia subgroups, the mean IOP was significantly higher in the rural group than in the urban group and in the inland group than in the coastal group. Table 3 shows the information of subgroups by refraction in more detail.

\section{Correlation of IOP with sex}

In the univariate analysis, female participants $(\mathrm{P}<0.001)$ had a higher IOP than did male participants. Regional stratification showed that the IOP was higher in females from rural and inland areas $(\mathrm{P}=0.0002$ and $<0.001)$ than in females from urban and coastal areas, respectively. The IOP was slightly higher in males $(\mathrm{P}=0.0459)$ from rural areas than in those from urban areas, but no significant difference was found between those living in coastal and inland areas $(\mathrm{P}=0.0884)$. Table 4 shows the information of subgroups by sex in more detail. 


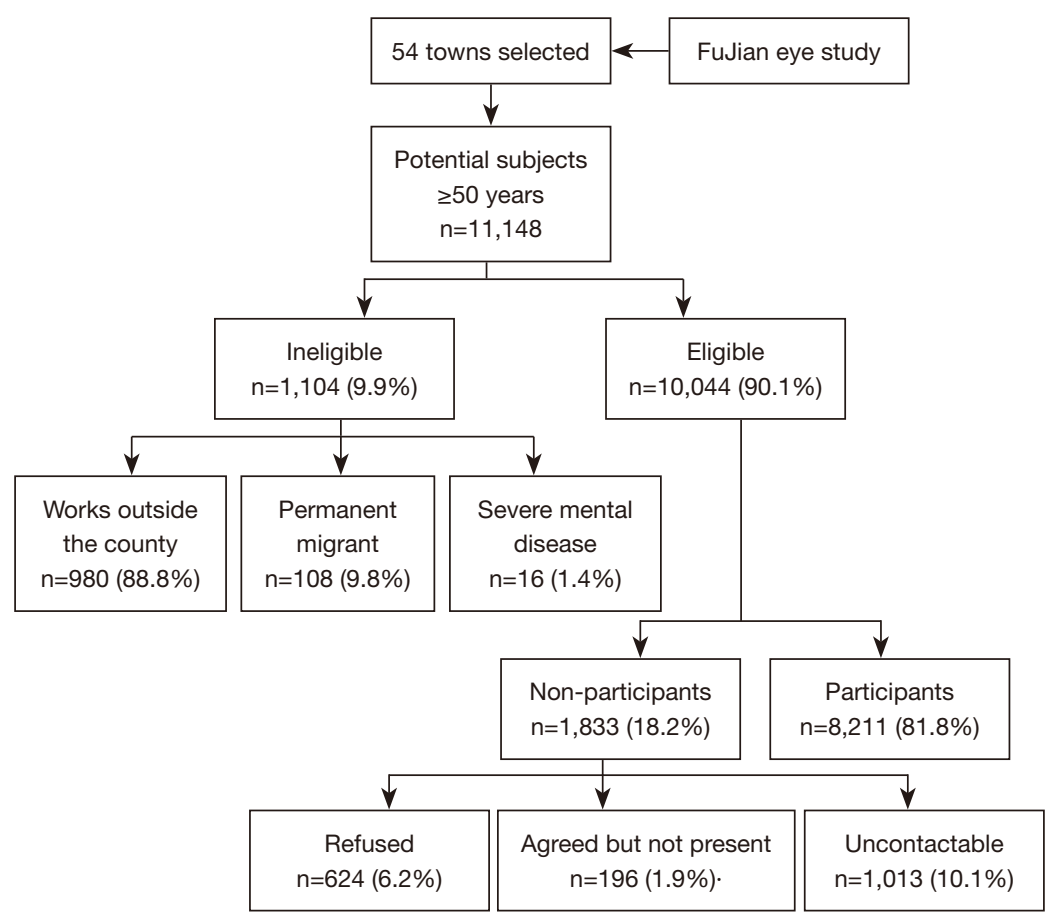

Figure 1 Flowchart of recruitment for the Fujian Eye Study.

\section{Correlations of IOP with chronic diseases history, BMI, $H R, S B P$, and diastolic blood pressure (DBP)}

An association was also observed between IOP and a history of chronic diseases $(\mathrm{P}<0.001)$. Regional stratification showed that both among participants with a chronic disease history and those without, the IOP was higher in the rural and inland groups than in the urban and coastal groups, respectively (Table 4). In the linear regression analysis, IOP was positively correlated with $\mathrm{BMI}(\mathrm{r}=0.05, \mathrm{P}<0.001)$, HR $(\mathrm{r}=0.10, \mathrm{P}<0.001)$, SBP $(\mathrm{r}=0.14, \mathrm{P}<0.001)$, and DBP $(\mathrm{r}=0.13$, $\mathrm{P}<0.001)$. Differentiating participants into the urban and rural groups or the coastal and inland groups produced similar results.

\section{Correlation of IOP with smartphone use in the dark}

Using a smartphone in the dark was also found to be associated with IOP $(\mathrm{P}<0.001)$. Regional stratification showed that both among participants who used smartphone in the dark and those who did not, the IOP was higher in the rural and inland groups than in the urban and coastal groups, respectively (Table 4).

\section{Correlation of IOP with tobacco, alcohol, and tea consumption}

IOP was found to be associated with alcohol consumption $(\mathrm{P}=0.011)$, but not with tobacco $(\mathrm{P}=0.5493)$ or tea $(\mathrm{P}=0.307)$ consumption. Regional stratification showed that among non-tobacco consumers, the IOP was higher in the rural and inland groups than in the urban and coastal groups, respectively. However, among tobacco consumers, IOP was independent from region (Table 4). Among non-alcohol consumers, the IOP was higher in the rural and inland groups than in the urban and coastal groups, respectively. However, among tobacco consumers, the IOP differed between the coastal and inland groups, but not between the urban and rural groups (Table 4). Further, among both tea consumers and non-tea consumers, the IOP was higher in the rural and inland groups than in the urban and coastal groups, respectively (Table 4).

\section{Multiple regression}

Multiple regression analysis including variables such as age, sex, region, refraction, smartphone use in the dark, a history 
Table 1 Composition of the Fujian Eye Study population

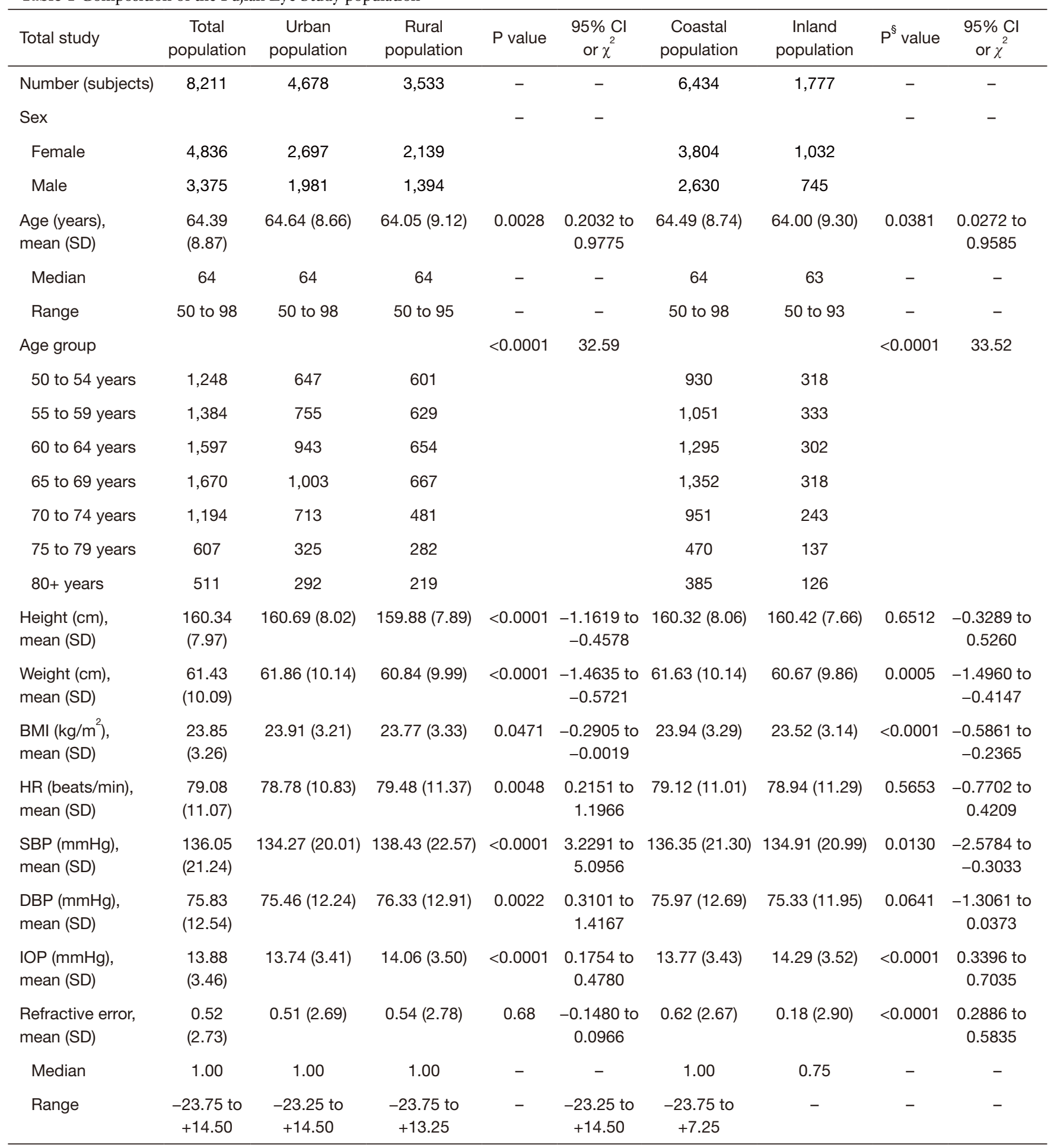

Table 1 (continued) 
Table 1 (continued)

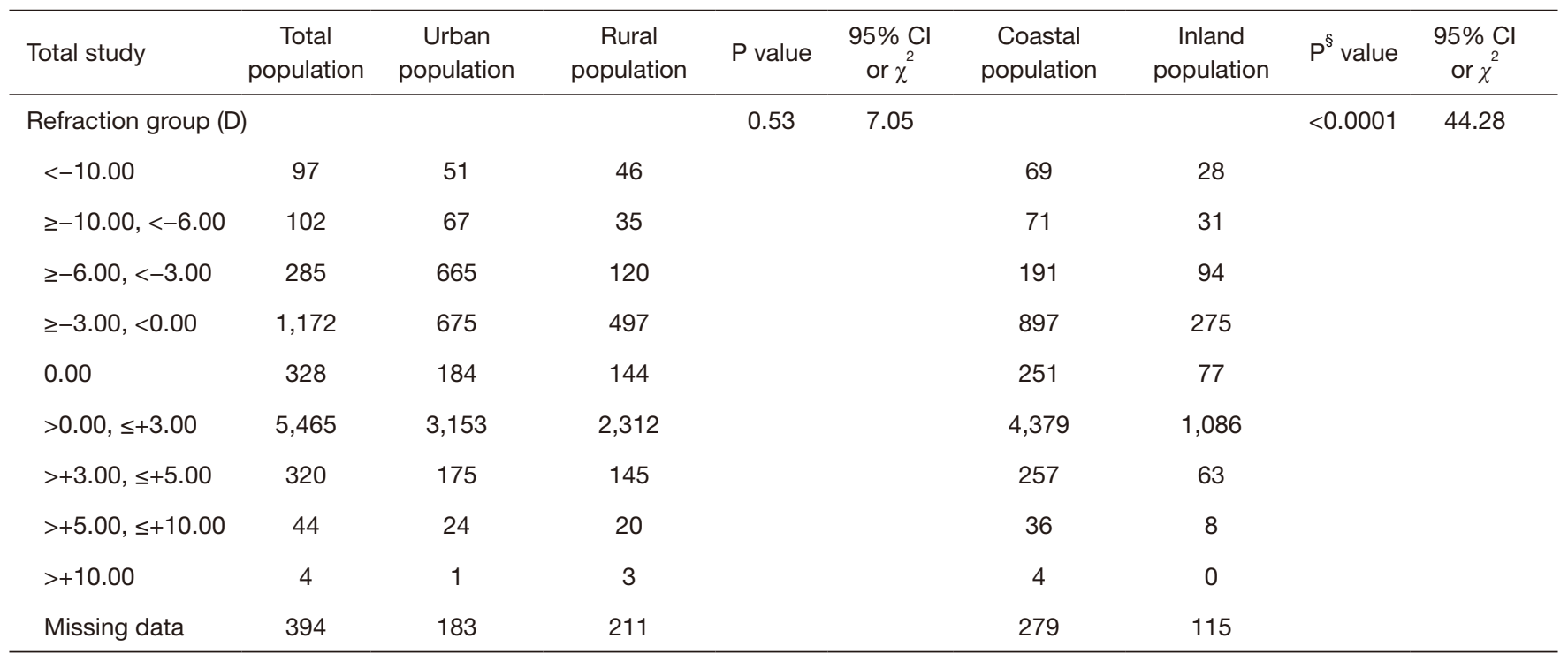

SD, standard deviation; BMI, body mass index; HR, heart rate; SBP, systolic blood pressure; DBP, diastolic blood pressure; IOP, intraocular pressure; $\mathrm{D}$, diopter; $\mathrm{Cl}$, confidence interval; $\chi^{2}$, the valve of Chi-square analysis; $\mathrm{P}$ value, statistical significance of the difference between urban population group and rural population group; $\mathrm{P}^{\S}$ value, statistical significance of the difference between coastal population group and inland population group.

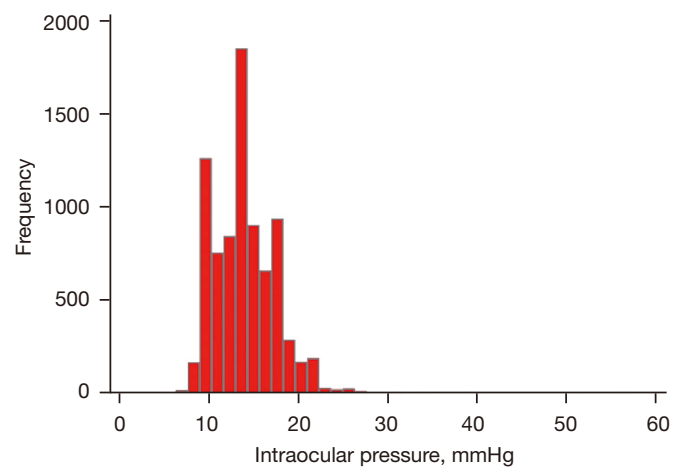

Figure 2 Histogram shows the distribution of intraocular pressure in the Fujian Eye Study.

of chronic disease, and alcohol consumption revealed that high IOP was significantly associated with older age $(\mathrm{P}<0.001)$, female sex $(\mathrm{P}=0.026)$, faster HR $(\mathrm{P}<0.001)$, higher SBP $(\mathrm{P}<0.001)$, increasing myopia $(\mathrm{P}<0.001)$, living in an inland region $(\mathrm{P}<0.001)$, smartphone use in the dark $(\mathrm{P}=0.009)$, and a chronic disease history $(\mathrm{P}=0.032)$. However, living in an urban or rural area $(\mathrm{P}=0.156)$, BMI $(\mathrm{P}=0.379)$, DBP $(\mathrm{P}=0.977)$, and alcohol consumption $(P=0.307)$ were no longer statistically correlated with IOP.

\section{Discussion}

Glaucoma is a long-term health problem worldwide, and increased IOP is the primary risk factor for the development and progression of this disease. In this study, the median IOP measured with an iCare RBT instrument was $14 \mathrm{mmHg}$, which is within the normal range $(13.88 \pm 3.46 \mathrm{mmHg})$ of 10 to $21 \mathrm{mmHg}$ (25). Although the median IOP value was slightly lower than those reported in most previous studies, including the Singapore Epidemiology of Eye Diseases Study (11), Beijing Eye Study (12), Handan Eye Study (13), Lingtou Eye Cohort Study (14), and Liwan Eye Study (26), it was within a similar CI.

Many previous studies on IOP $(3,4,10-14)$ focused on its correlations with age, refraction, sex, BMI, SBP, education level, income, and other sociodemographic factors, and ignored its correlations with health status and lifestyle habits. The present study attempted to fill this knowledge gap by not only confirming the correlations of IOP with age, sex, BMI, SBP and refraction, but also exploring the relationships between IOP and chronic disease history, region, and some lifestyle habits, such as smartphone use in the dark, and tobacco, alcohol, and tea consumption. The Beijing Eye Study (12) revealed that IOP was statistically 


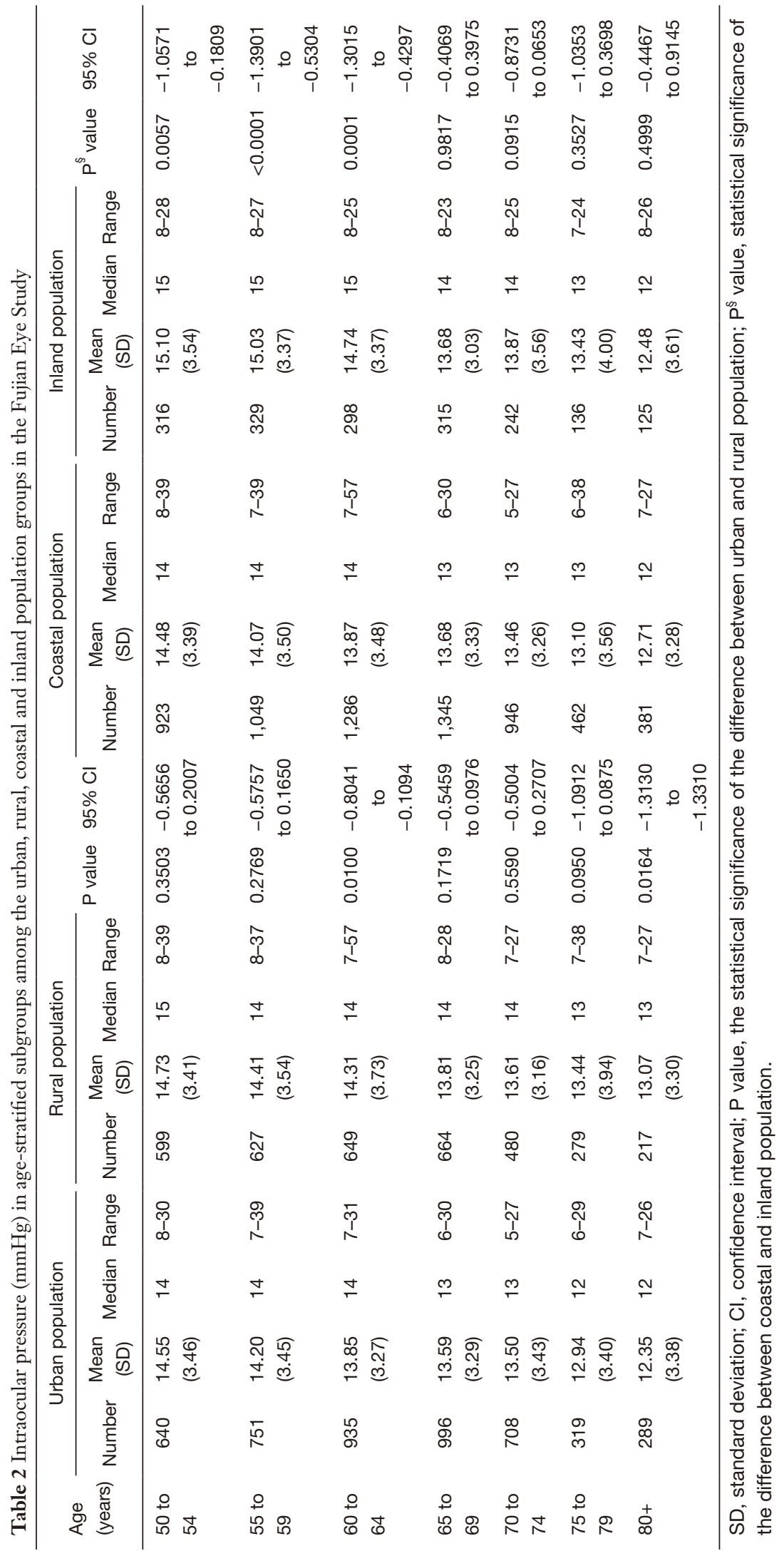




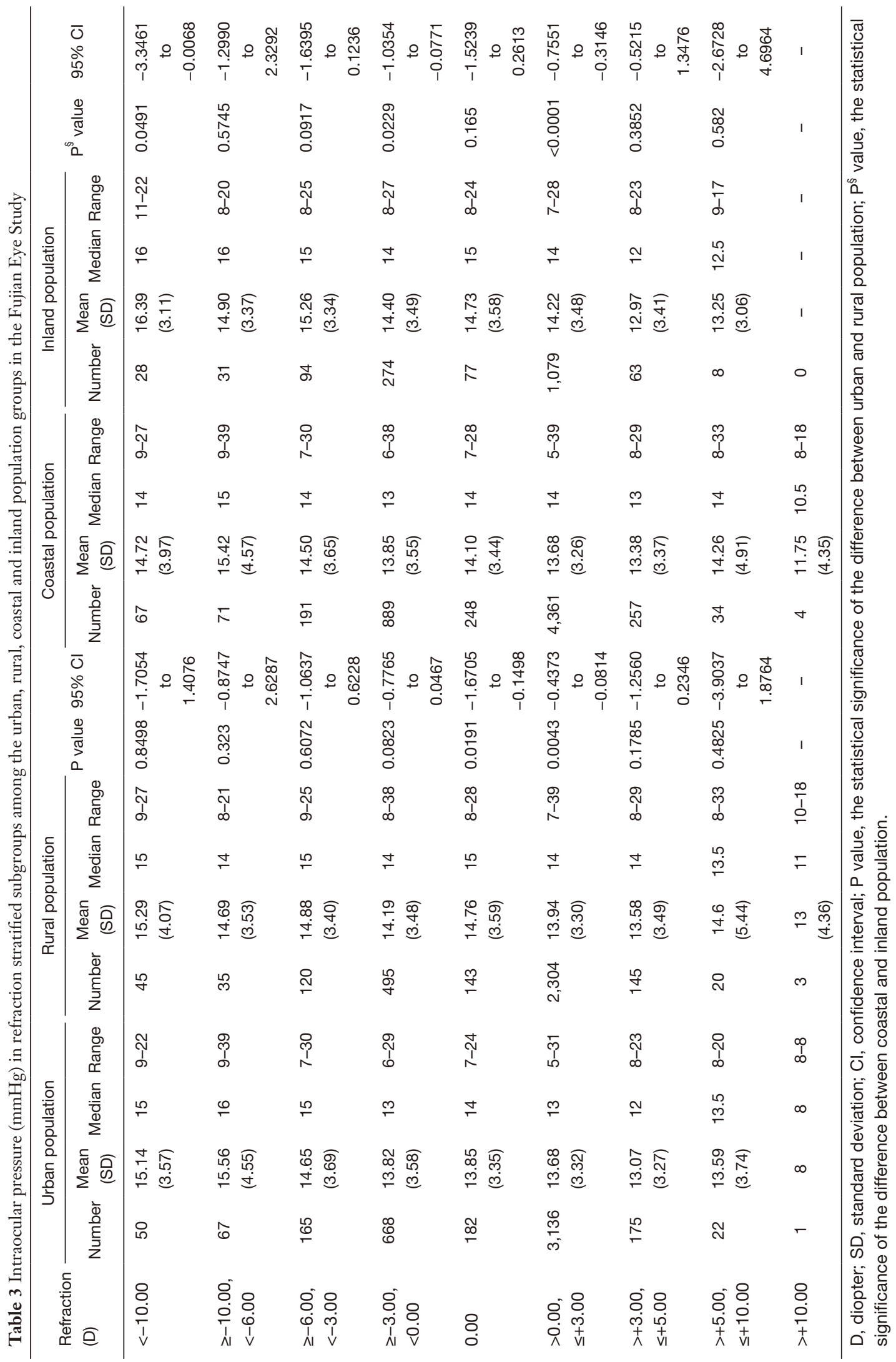




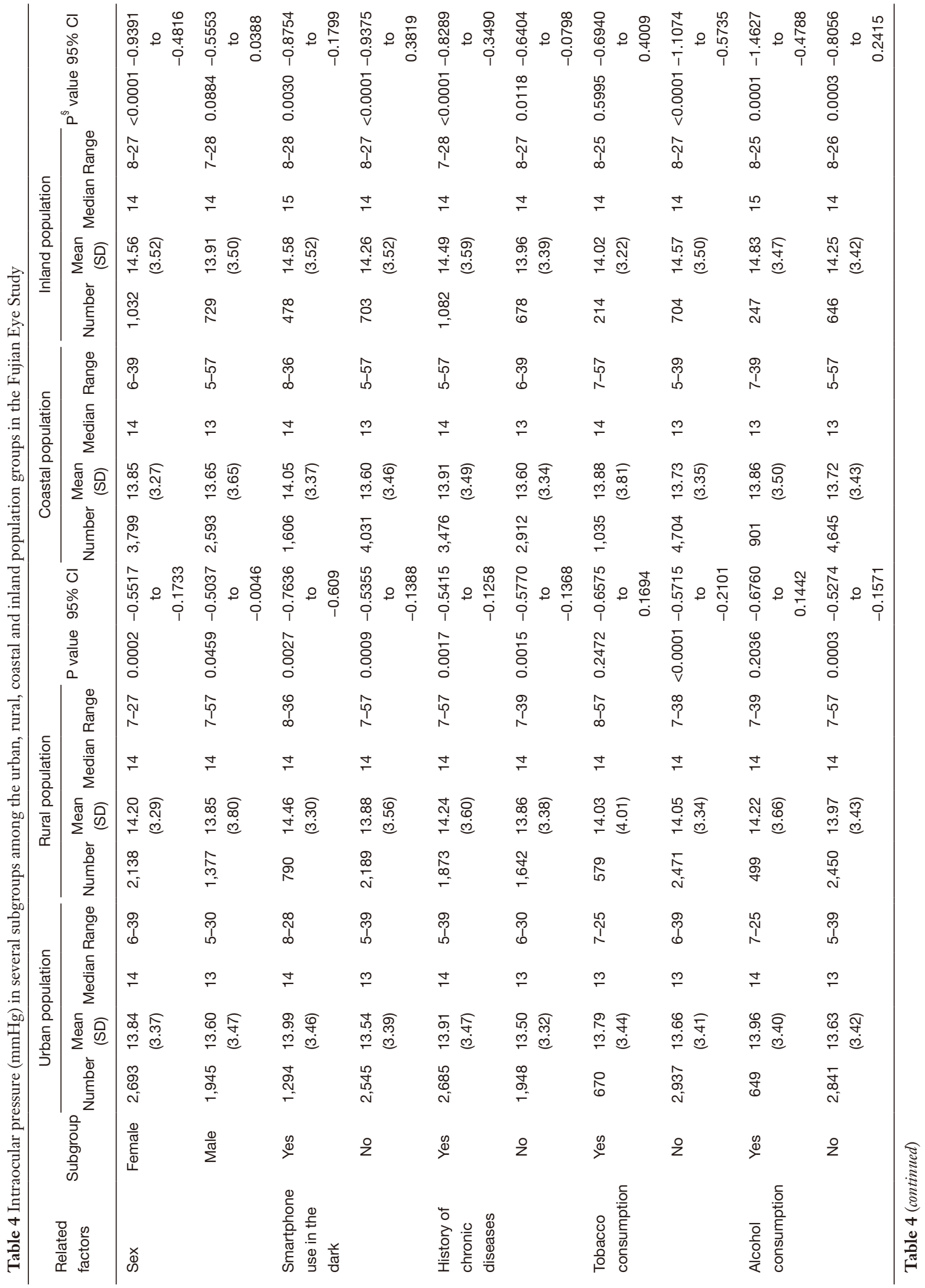




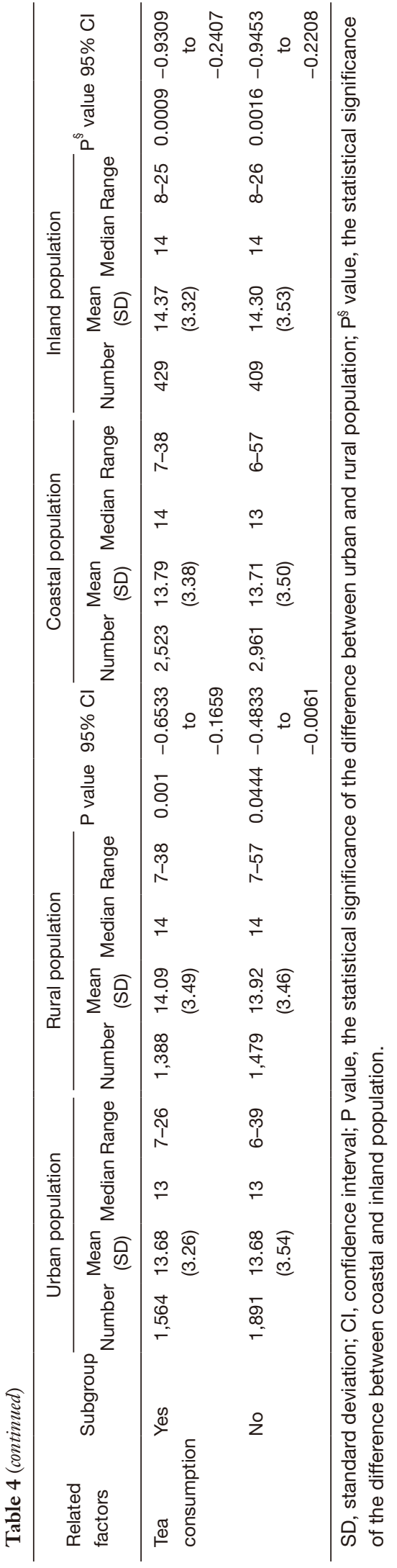

independent of living in a rural or urban area, which was consistent with our result. Although many studies have assessed IOP and its associations with various factors, few studies have assessed the differences between people living in coastal and inland regions.

Our study has confirmed the results of previous studies that found high IOP to be correlated with younger age, female sex, myopia, a faster HR, and higher SBP (3,10-14). However, some of our findings differed from previously reported results. Chan et al.'s (3) large cohort results from the UK Biobank showed that Goldmann-correlated IOP (IOPg) and corneal-compensated IOP (IOPcc) were both significantly associated with male sex. They also reported that the increase in both IOPg and IOPcc with age was greatest among individuals of mixed races, followed by Black and White individuals, suggesting that racial differences may be responsible for the difference in results. The Beijing Eye Study (12) revealed that IOP was statistically independent of sex. Tham et al. (11) found that individuals with the lowest quartile of SBP $(<124 \mathrm{mmHg})$ were 1.69 times more likely to have primary open angle glaucoma, while our study found that IOP was positively correlated with SBP. Other inconsistencies include the finding from multiple regression analysis that despite being related to IOP, BMI did not have a significant effect on IOP in our study participants. In a Korean population (27), IOP was found to increase with total cholesterol, triglyceride, and BMI, and to decrease only with age, regardless of sex. Linear regression of Liwan Eye Study (26) showed that the change in IOP over 10 years was not associated with baseline age, sex, BMI, central corneal thickness, spherical equivalence, hypertension, or diabetes. However, it was positively associated with longitudinal increase of BMI when longitudinal changes in $\mathrm{BMI}$ and spherical equivalence were included in the model. Deokule et al. (28) discussed how inconsistent definitions and designs, and differing population characteristics within studies have obfuscated definitive conclusions. Uniform standards therefore need to be developed for future evaluation and comparison.

Encouragingly, our study has produced some new findings. According to our results, there were no significant differences in IOP between the urban and rural groups or the inland and coastal groups after stratification by age and refraction. However, there were significant differences in IOP between the urban and rural groups and the coastal and inland groups with regard to smartphone use in the dark, chronic disease history, and alcohol and 
tea consumption. These findings evidence that regional lifestyle differences do affect eye health, although age and refraction both have a stronger bearing on IOP than does region. Differences in income levels, education levels, transportation modes, and environmental and lifestyle factors, such as high ultraviolet exposure and a seafoodrich coastal diet (19-21), may be important factors affecting changes in IOP. All these results suggest that further indepth investigations of the impacts of environmental factors on IOP are needed to better formulate regional policies for improving eye health in different geographical environments. Moreover, according to the Statistical Bulletin of Social Service Development in 2016 (29), by the end of that year, there were 230 million people aged 60 and above in China, and by 2040, it is estimated that China's elderly population will reach 397 million. With China's aging population, the development of smartphones which are suitable for use by older individuals is of crucial importance and letting the elderly have their own concerns to do is extremely important for social stability and development. Smartphones designed for older people are still relatively scarce, but may become a new hotspot for design in the electronic product market. Another novel point was that IOP was associated with chronic disease history after taking into account the interdependency of the parameters. There were several reports on relationship between IOP and chronic diseases, however, these reports mostly focused on a single disease (30-33), and there were no relevant reports on population-based data. Our study was a population based cross sectional survey, and it can objectively reflect the correlation between IOP and chronic diseases, provide practical data support for basic research, and attract the attention of policy-making.

Some limitations exist in the present study. Notably, the IOP was measured using a handheld RBT, which may complicate efforts to draw direct comparisons with other epidemiological studies (3-10). However, the iCare RBT has similar accuracy to the Goldmann tonometer $(34,35)$, and its use may not have influenced other IOP results, such as the IOP distribution in the Gaussian-like distribution curve, age distribution, sex distribution, and coastal versus inland and rural versus urban distributions. Other limitations were that central corneal thickness was not measured and that only cross-sectional results are presented. As discussed in an earlier systematic review and meta-analysis to directly compare studies assessing the agreement between one or more tonometer (36), the results of a cross-sectional analysis may differ from those of a longitudinal analysis.

\section{Conclusions}

The FJES results show that IOP is higher in individuals over 50 years who are younger and female, those who live inland, those who use a smartphone in the dark, and those with myopia, a higher SBP, a faster HR, or a history of chronic diseases than in other individuals. Unlike most previous studies, which focused on insufficiencies and inequalities in education, medical care, income, and other aspects, this study has focused on and revealed correlations between IOP and chronic diseases and smartphone use in the dark. Policy development, service delivery, research, and evaluation for improving eye health should also account for regional disparities. Further research is needed to better understand the related mechanisms of systemic diseases and eye diseases and to find more effective ways to protect our eye health.

\section{Acknowledgments}

We thank all Fujian Eye Study (FJES) group members for their tremendous effort in making this study successful, especially in the field of examinations and data collection. Funding: This research was supported by the National Natural Science Foundation of China (NSFC, No. 81870672), National Natural Science Foundation of China Youth Fund (NSFC, No. 81900881), Natural Science Foundation of Youth Innovation Program of Fujian Province (No. 2019D007 and No. 2020D028), Medical and Healthcare Guiding Program of Xiamen City (No. 3502Z20189018) and Xiamen Science and Technology Planning Project (No. 3502Z20184023). These funding organizations had no role in the study design, or the collection, analysis, or interpretation of the data.

\section{Footnote}

Reporting Checklist: The authors have completed the STROBE reporting checklist. Available at https://dx.doi. org/10.21037/apm-21-3238

Data Sharing Statement: Available at https://dx.doi. org/10.21037/apm-21-3238

Conflicts of Interest: All authors have completed the ICMJE uniform disclosure form (available at https://dx.doi. org/10.21037/apm-21-3238). The authors have no conflicts of interest to declare. 
Ethical Statement: The authors are accountable for all aspects of the work in ensuring that questions related to the accuracy or integrity of any part of the work are appropriately investigated and resolved. Approval for the study was granted by the Ethics Committee of Xiamen Eye Center affiliated with Xiamen University (approval No. XMYKZX-KY-2018-001). The study was conducted in accordance with the Declaration of Helsinki (as revised in 2013). Written informed consent was obtained from all study participants.

Open Access Statement: This is an Open Access article distributed in accordance with the Creative Commons Attribution-NonCommercial-NoDerivs 4.0 International License (CC BY-NC-ND 4.0), which permits the noncommercial replication and distribution of the article with the strict proviso that no changes or edits are made and the original work is properly cited (including links to both the formal publication through the relevant DOI and the license). See: https://creativecommons.org/licenses/by-nc-nd/4.0/.

\section{References}

1. Bol P. Glaucoma. Ned Tijdschr Tandheelkd 2003;110:2989.

2. Weinreb RN, Aung T, Medeiros FA. The pathophysiology and treatment of glaucoma: a review. JAMA 2014;311:1901-11.

3. Chan MP, Grossi CM, Khawaja AP, et al. Associations with Intraocular Pressure in a Large Cohort: Results from the UK Biobank. Ophthalmology 2016;123:771-82.

4. Mitchell R, Rochtchina E, Lee A, et al. Iris color and intraocular pressure: the Blue Mountains Eye Study. Am J Ophthalmol 2003;135:384-6.

5. Klein BE, Klein R, Knudtson MD. Intraocular pressure and systemic blood pressure: longitudinal perspective: the Beaver Dam Eye Study. Br J Ophthalmol 2005;89:284-7.

6. Xu BY, Burkemper B, Lewinger JP, et al. Correlation between Intraocular Pressure and Angle Configuration Measured by OCT: The Chinese American Eye Study. Ophthalmol Glaucoma 2018;1:158-66.

7. Cheng JW, Zong Y, Zeng YY, et al. The prevalence of primary angle closure glaucoma in adult Asians: a systematic review and meta-analysis. PLoS One 2014;9:e103222.

8. Yip JL, Foster PJ. Ethnic differences in primary angleclosure glaucoma. Curr Opin Ophthalmol 2006;17:175-80.

9. Lee RY, Chon BH, Lin SC, et al. Association of ocular conditions with narrow angles in different ethnicities. Am J Ophthalmol 2015;160:506-515.e1.

10. Wang D, Huang G, He M, et al. Comparison of anterior ocular segment biometry features and related factors among American Caucasians, American Chinese and mainland Chinese. Clin Exp Ophthalmol 2012;40:542-9.

11. Tham YC, Lim SH, Gupta P, et al. Inter-relationship between ocular perfusion pressure, blood pressure, intraocular pressure profiles and primary open-angle glaucoma: the Singapore Epidemiology of Eye Diseases study. Br J Ophthalmol 2018;102:1402-6.

12. $\mathrm{Xu} \mathrm{L}, \mathrm{Li}$ J, Zheng $\mathrm{Y}$, et al. Intraocular pressure in Northern China in an urban and rural population: the Beijing eye study. Am J Ophthalmol 2005;140:913-5.

13. Zhou Q, Liang YB, Wong TY, et al. Intraocular pressure and its relationship to ocular and systemic factors in a healthy Chinese rural population: the Handan Eye Study. Ophthalmic Epidemiol 2012;19:278-84.

14. Han X, Yang T, Zhang J, et al. Longitudinal changes in intraocular pressure and association with systemic factors and refractive error: Lingtou Eye Cohort Study. BMJ Open 2018;8:e019416.

15. Song $\mathrm{P}$, Wang $\mathrm{H}$, Theodoratou $\mathrm{E}$, et al. The national and subnational prevalence of cataract and cataract blindness in China: a systematic review and meta-analysis. J Glob Health 2018;8:010804.

16. Jonas JB, Cheung CMG, Panda-Jonas S. Updates on the Epidemiology of Age-Related Macular Degeneration. Asia Pac J Ophthalmol (Phila) 2017;6:493-7.

17. Ghasemi Fard S, Wang F, Sinclair AJ, et al. How does high DHA fish oil affect health? A systematic review of evidence. Crit Rev Food Sci Nutr 2019;59:1684-727.

18. Joachim N, Mitchell P, Burlutsky G, et al. The Incidence and Progression of Age-Related Macular Degeneration over 15 Years: The Blue Mountains Eye Study. Ophthalmology 2015;122:2482-9.

19. Vergneau-Grosset C, Péron F. Effect of ultraviolet radiation on vertebrate animals: update from ethological and medical perspectives. Photochem Photobiol Sci 2020;19:752-62.

20. Bose B, Najwa AR, Shenoy P S. Oxidative Damages to Eye Stem Cells, in Response to, Bright and Ultraviolet Light, Their Associated Mechanisms, and Salvage Pathways. Mol Biotechnol 2019;61:145-52.

21. Williams KM, Bentham GC, Young IS, et al. Association Between Myopia, Ultraviolet B Radiation Exposure, Serum Vitamin D Concentrations, and Genetic Polymorphisms in Vitamin D Metabolic Pathways in a Multicountry 
European Study. JAMA Ophthalmol 2017;135:47-53.

22. Geng $\mathrm{Y}, \mathrm{Z}$ Zhoo N. Measurement of sustainable higher education development: Evidence from China. PLoS One 2020;15:e233747.

23. Ren Y, Fang C, Lin X, et al. Evaluation of the ecoefficiency of four major urban agglomerations in coastal eastern China. Journal of Geographical Sciences 2019;29:1315-30.

24. Small C. Global population distribution and urban land use in geophysical parameter space. Earth Interactions 2004;8:1-18.

25. Friberg TR. Ocular effects of gravity inversion. West J Med 1985;143:530-1.

26. Han X, Zhao H, Wu C, et al. Ten-year changes of intraocular pressure in adults: the Liwan Eye Study. Clin Exp Ophthalmol 2019;47:41-8.

27. Han YS, Lee JW, Lee JS. Intraocular pressure and influencing systemic health parameters in a Korean population. Indian J Ophthalmol 2014;62:305-10.

28. Deokule S, Weinreb RN. Relationships among systemic blood pressure, intraocular pressure, and open-angle glaucoma. Can J Ophthalmol 2008;43:302-7.

29. Ministry of Civil Affairs of the People's Republic of China (2017). Available online: http://www.mca.gov.cn/article/ xw/mzyw/201708/20170815005382.shtml (Accessed 16 September 2021)

30. Chen YF, Zheng JJ, Qu C, et al. Inonotus obliquus

Cite this article as: $\mathrm{Li} \mathrm{Y,} \mathrm{Hu} \mathrm{Q,} \mathrm{Li} \mathrm{X,} \mathrm{Hu} \mathrm{Y,} \mathrm{Wang} \mathrm{B,} \mathrm{Qin}$ $\mathrm{X}, \mathrm{Ren} \mathrm{T}$. Intraocular pressure of adults in a coastal province in southern China: the Fujian cross-sectional eye study. Ann Palliat Med 2021;10(12):12390-12402. doi: 10.21037/apm-21-3238 polysaccharide ameliorates dextran sulphate sodium induced colitis involving modulation of Th1/Th2 and Th17/Treg balance. Artif Cells Nanomed Biotechnol 2019;47:757-66.

31. Vargas D, Castro C. Pupillometry in Chagas disease. Arq Bras Oftalmol 2018;81:195-201.

32. Chelala E, Dirani A, Fadlallah A, et al. Effect of hemodialysis on visual acuity, intraocular pressure, and macular thickness in patients with chronic kidney disease. Clin Ophthalmol 2015;9:109-14.

33. Aytekin F, Yildiz Gulhan P, Teberik K, et al. The effects of non-invasive mechanic ventilator modes on intraocular pressure in COPD patients with hypercapnic respiratory failure. Clin Respir J 2020;14:165-72.

34. Özcura F, Yildirim N, Şahin A, et al. Comparison of Goldmann applanation tonometry, rebound tonometry and dynamic contour tonometry in normal and glaucomatous eyes. Int J Ophthalmol 2015;8:299-304.

35. Chen M, Zhang L, Xu J, et al. Comparability of three intraocular pressure measurement: iCare pro rebound, non-contact and Goldmann applanation tonometry in different IOP group. BMC Ophthalmol 2019;19:225.

36. Cook JA, Botello AP, Elders A, et al. Systematic review of the agreement of tonometers with Goldmann applanation tonometry. Ophthalmology 2012;119:1552-7.

(English Language Editor: J. Reylonds) 